\title{
EL ANTIGUO MONASTERIO AGUSTINIANO DE SAN MIGUEL ACATLAN
}

\section{Por Manuel Romero de Terreros}

Al Amanecer y cuando cae la tarde, se esparce por el plácido ambiente de los pueblos y haciendas circunvecinos la voz de las campanas de Acatlán. Aunque no son tan antiguas como el campanario del que cuelgan, puesto que apenas datan de poco más de un siglo, parecen quejarse del abandono en que se encuentra el vetusto monasterio.

En efecto, más de la mitad de éste se ha derrumbado: de la antigua y suntuosa iglesia, sólo quedan rastros pero se sabe que era de gran tamaño, con cubierta de amplia bóveda de cañón, ábside de planta poligonal y hermoso imafronte sobre amplio atrio, limitado éste por bardas almenadas, en el que aún existen tres típicas capillas-posas en los ángulos, y en su centro una gran cruz monolítica.

Pero los recios muros que quedan dan fe de la suntuosidad y solidez con que los agustinos erigían sus edificios monacales.

Cuán vetusto es el monasterio de Acatlán, nos lo dice fray Jerónimo. Román en su Chrónica de la Orden de los Ermitaños del Glorioso Padre Sancto Agustin, impresa en Salamanca, en 1659, con estas palabras: "Año de 1557. Celebróse el 9 Capítulo en Indias, en Ocuituco en el mesmo día y año que en Castilla: Salió en provincial el muy reverendo. padre maestro fray Alonso de Ia Veracruz, puso frayles en Acatlán que estaba de visita, que es como de prestado: tomó de nuevo los monasterios siguientes, la Ermita y Chapuloacán, y Metlapeque, y Vayacocotla."

En cuanto al pueblo mismo de San Miguel Acatlán, hoy cabecera de la municipalidad de su nombre del distrito de Tulancingo, Estado de Hidalgo, debe de haber sido fundado según opinión competente, por los toltecas, antes de la conquista. El primer libro de matrimonios. del archivo parroquial data de 1569 y su doctrina abarcaba antaño numerosos pueblos y haciendas de los aledaños.

La silueta que desde lejos presenta el monasterio es la de un macizo de piedra, casi sin salientes; solamente unas insignificantes ventanas. interrumpen la monotonía de los lisos muros. En el interior, circundan un pequeño patio, claustros altos y bajos de sencillísima disposición arquitectónica, con arcos de medio punto sobre pilares lisos y bóvedas de cañón.

$\therefore$ Para hacer las veces de la desaparecida iglesia se derribó el muro 
que separaba la Sala de profundis del Refectorio; de esta manera quedó la actual parroquia alojada en una especie de túnel, ya que la larga nave resultante, con bóveda de cañón seguido, no guarda proporción con su anchura y poca elevación. Pobre es el adorno de su altar de piedra, pero grande el fervor de los feligreses, en su mayoría indígenas, que acuden a orar ante él.

Afortunadamente se conservan algunas de las ricas casullas y dalmáticas de la antigua iglesia. ${ }^{2}$

Las bóvedas de la portería y otras dependencias conservan todavía parte de su curiosa ornamentación, pintada al falso fresco, a manera de casetones poligonales en que predominan los colores rojo, azul y negro, como en muchos otros monasterios agustinianos, entre ellos el magnifico decorado del claustro bajo de Atlatlauhcan, en el Estado de Morelos.

Una escalera en espiral, o "de caracol", como vulgarmente se dice, resulta por demás extraña, puesto que, construida toda ella de madera, su vástago se ha torcido de manera alarmante, y produce insólita sensación el ascender por ella a la azotea del antiguo monasterio, una azotea casi plana, en la cual lo primero que se ve es la espadaña, cuyas lenguas de bronce parecen quejarse al amanecer y cuando se pone el sol.

1 Luis Azcué Mancera, Manuel Toussaint y Justino Fernández. Catálogo de consarwciones religiosas del Estado de Hidalgo. México, Secretarla de Hacienda, mcmXL. 
DOI: http://dx.doi.org/10.22201/iie.18703062e.1965.34.803

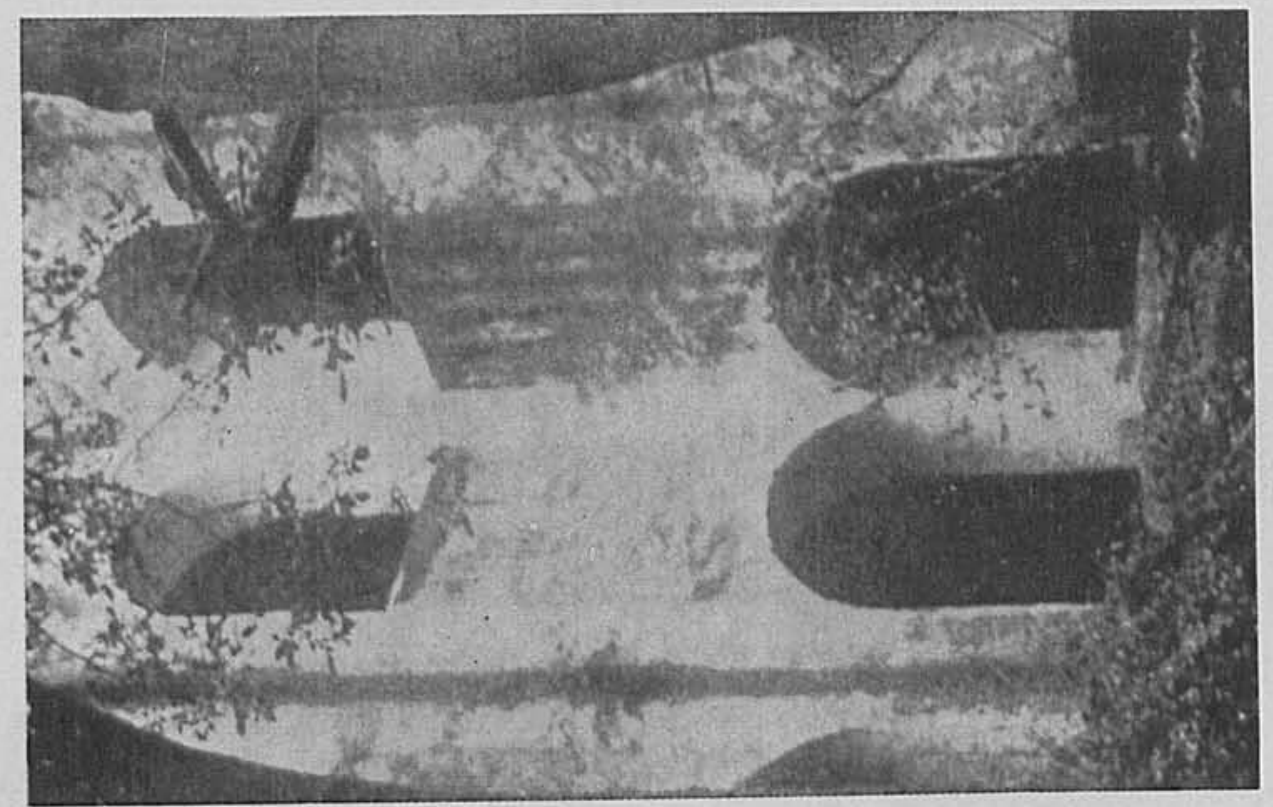

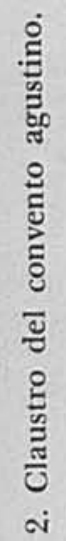

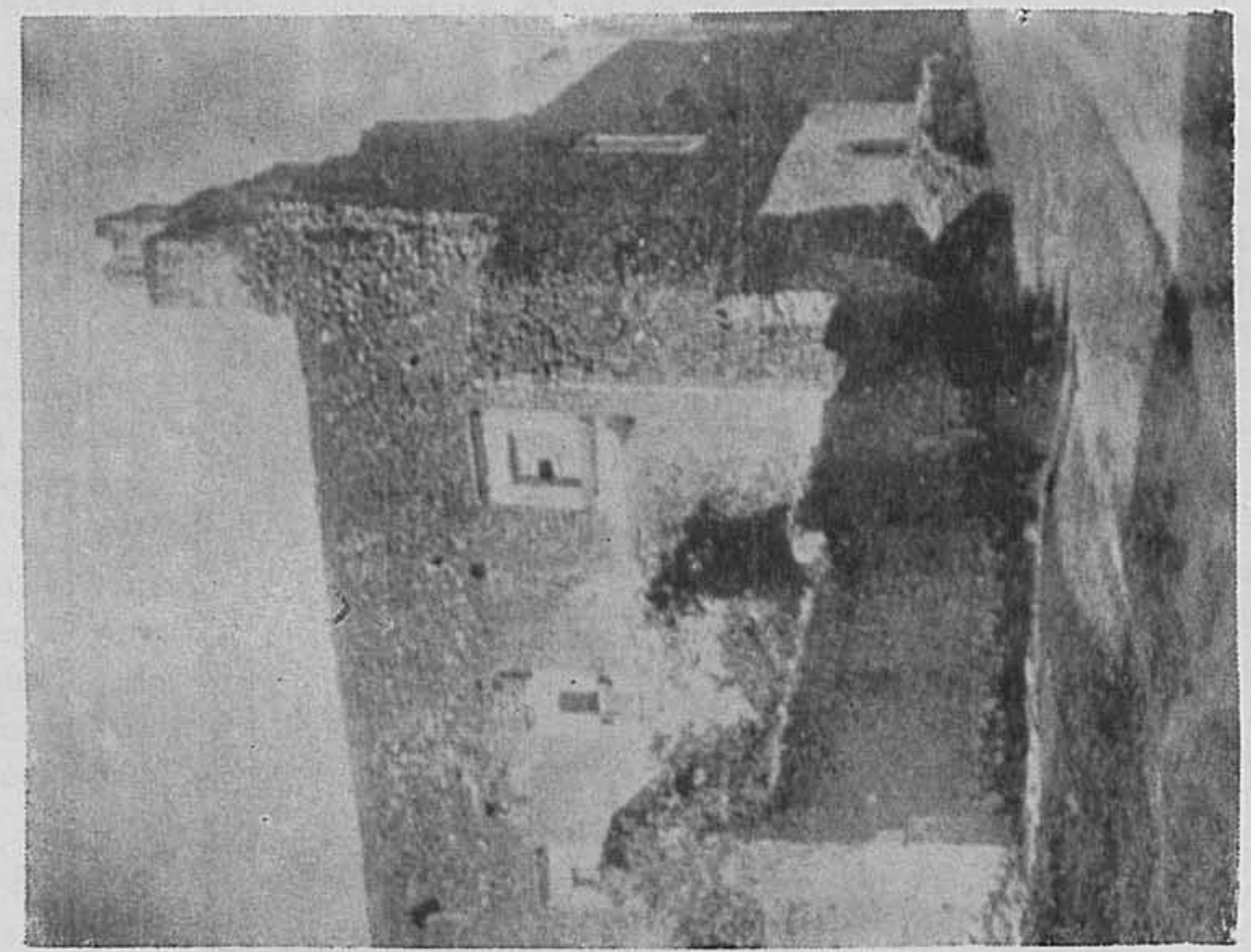

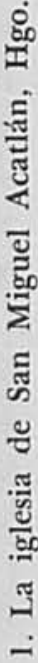




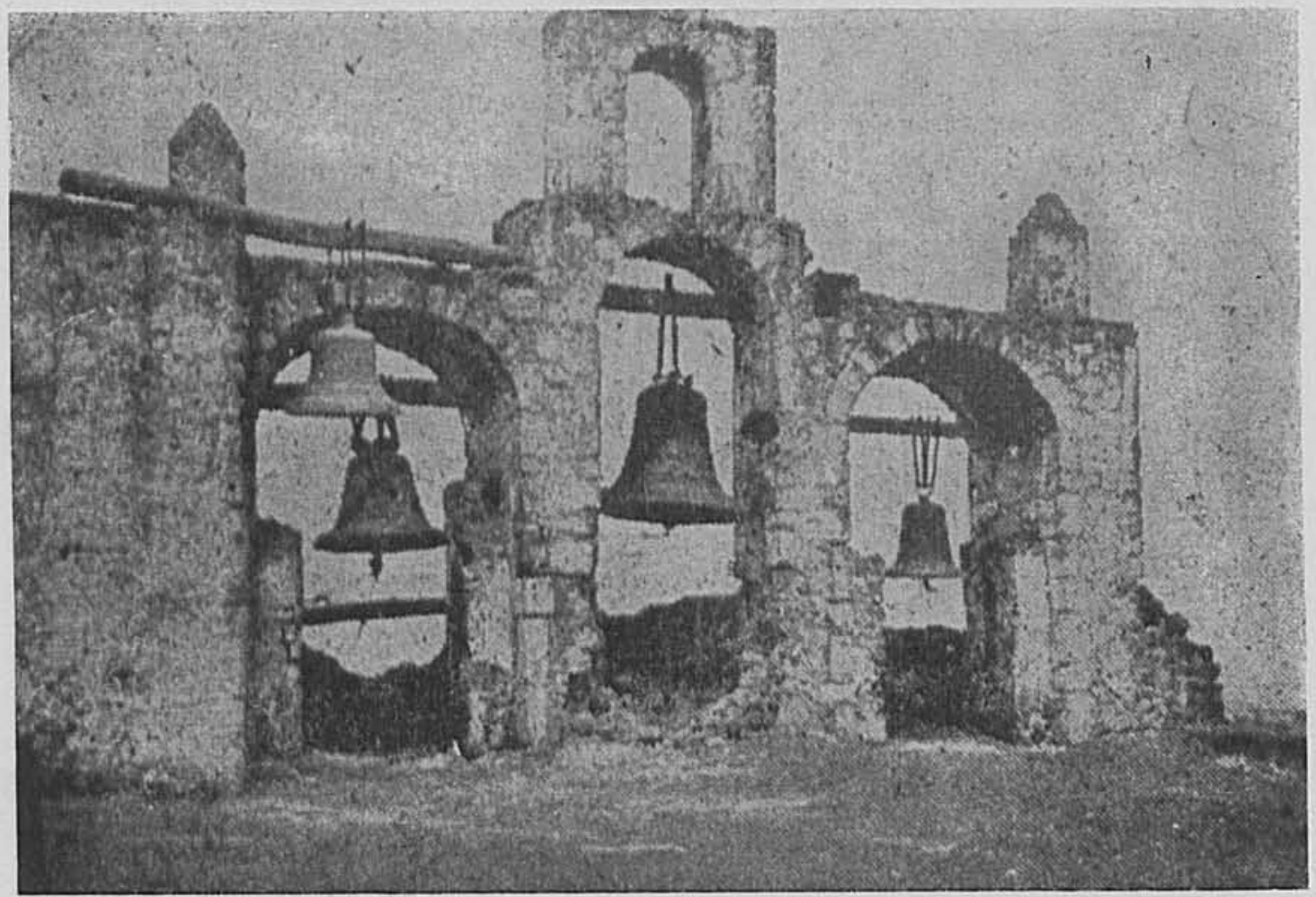

3. San Miguel Acatlán. Espadaña.

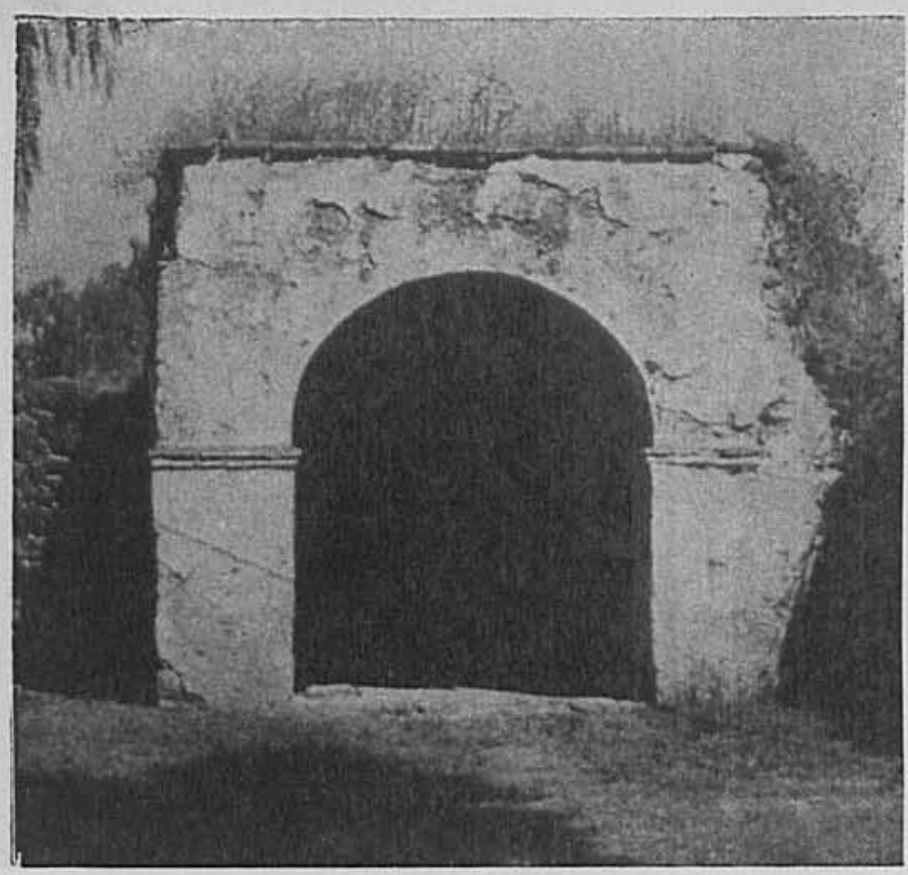

4. Capilla posa en el atrio. 